\title{
Household Food Insecurity, Low Dietary Diversity, and Early Marriage Were Predictors for Undernutrition among Pregnant Women Residing in Gambella, Ethiopia
}

\author{
Mamo Nigatu $(\mathbb{D}$, Tsegaye Tewelde Gebrehiwot $\mathbb{D}$, and Desta Hiko Gemeda \\ Department of Epidemiology, Institute of Health, Jimma University, Jimma, Ethiopia \\ Correspondence should be addressed to Mamo Nigatu; mamogebre14@gmail.com
}

Received 18 August 2017; Accepted 21 December 2017; Published 18 January 2018

Academic Editor: Ronald J. Prineas

Copyright (c) 2018 Mamo Nigatu et al. This is an open access article distributed under the Creative Commons Attribution License, which permits unrestricted use, distribution, and reproduction in any medium, provided the original work is properly cited.

Background. Maternal undernutrition affects the health of both mothers and children and, as a result, has broad impacts on economic and social development. Objective. The aim of this study was to assess magnitude of undernutrition and associated factors among pregnant women in Gambella town, 2014. Methods. Community based cross-sectional study was conducted on 338 randomly selected pregnant women from March to April 2014. Bivariate and multivariable logistic regressions were used for data analysis. Result. The prevalence of undernutrition among pregnant women in Gambella town was 28.6\%. Pregnant women who were married before their age of eighteen, who were from food insecure households, and who had low dietary diversity score were nearly four ( $\mathrm{AOR}=3.9,95 \% \mathrm{CI}: 2.2-6.9)$, two $(\mathrm{AOR}=2.3,95 \% \mathrm{CI}: 1.2-3.6)$, and two (AOR = 2.1, 95\% CI: 1.3-4.16) times more likely to be undernourished as compared to their counterparts, respectively. Conclusion. Prevalence of undernutrition among pregnant women in Gambella town was unacceptably high. Stake holders should give due consideration to health education to delay age at first marriage and mainstreaming and strengthening nutritional activities that contribute to reduction of food insecurity and consumption of unbalanced nutrients.

\section{Introduction}

Nutrition is a fundamental pillar of human life, health, and development across the lifespan. From the earliest stage of fetal development, at birth through infancy, childhood, and adolescence, and into adulthood and old age, proper food and good nutrition are essential for survival, physical growth, mental development, performance and productivity, health, and well-being. It is an essential foundation of human and national development. For this reason everybody is expected to get adequate nutrition, especially woman of child bearing age $[1,2]$. Pregnancy is one of the most critical and unique periods in woman's life cycle. A woman's body changes dramatically during pregnancy; hence there is a strong need to balance these changes with an adequate and nutritious diet [3].

Nutrients need typically an increase during pregnancy and lactation than during any other stage in woman's adult life. Additional nutrients are required during gestation for growth of the fetus as well as for the development of maternal tissues that support fetal development. The nutritional ingredients required for this rapid growth and development depend on the support from maternal diet $[4,5]$. Proper dietary balance is necessary to ensure sufficient energy intake for adequate growth of the fetus without drawing on mother own tissues to maintain her pregnancy [6]. The common maternal nutritional problems during pregnancy include protein energy malnutrition, iron and folic acid deficiency, vitamin A deficiency, iodine deficiency, zinc deficiency, and vitamin B6 and vitamin B12 deficiency $[4,7]$.

Maternal undernutrition affects the health of both mother and children and, as a result, has broad impacts on economic and social development [7-10]. Undernourished pregnant woman has higher reproductive risks including death during or after child birth $[6,7,11]$. Many women suffer from combination of chronic energy deficiency, poor weight gain 
during pregnancy, anemia, and other micronutrient deficiency. These along with inadequate obstetric care contribute to high rates of maternal mortality and poor pregnancy outcomes [8, 12]. Maternal malnutrition in both the form of chronic energy and micronutrient deficiencies causes intrauterine growth retardation (IUGR), low birth weight, prematurity, infant and neonatal mortality, abortion, stillbirth, reduced physical activity, and poor cognitive development of the baby leading to poor educational capability and performance $[2,13-15]$.

Undernutrition's most damaging effect occurs during pregnancy and in the first two years of life, and the effect of this early damage on health, brain development, intelligence, educability, and reproductive is largely irreversible $[6,7,9]$. Maternal undernutrition has also intergenerational effect. Undernourished girls have a great likelihood of becoming undernourished mothers who in turn have a great chance of giving birth to low birth weight babies perpetuating an intergenerational cycle $[4,6]$.

Every day 800 women die during pregnancy or child birth and 8000 newborn babies die during their first month of life. Ninety-eight percent of newborn deaths and ninetynine percent of maternal death occur in developing countries [16]. Many women in developing countries maintain pregnancies on dietary intake lower than those recommended by international agencies [17]. In a systematic review including sixty-two studies published from 1989 to 2011 Lee et al. reported that a large majority of pregnant women from Africa and Asia had taken lower energy and micronutrient than those recommended by Food and Agricultural Organization/World Health Organization (FAO/WHO). Lee et al. concluded that the problems of unbalanced macronutrient profiles and multiple micronutrient deficiencies are common among pregnant women in developing countries across the region of the world [18].

Studies have shown that cultural factors including lack of care for pregnant women, increased workloads, early marriage, and teenage marriage make the situation worse in Ethiopia [2, 7]. In order to identify, prioritize, and avert the devastating risk of malnutrition the government of Ethiopia has designed the national nutrition strategy (NNS) of which maternal nutrition during pregnancy is one of the priority areas [7].

In supporting the national nutrition strategy and other potential intervention programs, adequate evidence about undernutrition and its contextual determinants in children, pregnant, and lactating mothers are available in the highlands of Ethiopia [11, 19-22]. However, there is no evidence about the aforementioned problem in pregnant women in lowlands of the country like Gambella region as to the investigators knowledge. Gambella region is characterized by having hot climate condition, relative insecurity, diverse ethnicity, low sociodemographic and economic characteristics, pastoralist community, and common natural disasters like drought and flooding [23]. Therefore, this study was aimed at determining undernutrition and its contextual risk factors among pregnant mothers in Gambella town, a low land in Southwest Ethiopia.

\section{Methods and Materials}

2.1. Study Setting. Data were collected from March to April 2014 in Gambella town, Southwest Ethiopia. Gambella town is a separate district and the capital of the Gambella Region located at the confluence of the Baro River and its tributary the Jajjaba. The town has a latitude and longitude of $8^{\circ} 15^{\prime} \mathrm{N}$ $34^{\circ} 35^{\prime} \mathrm{E}$ and has an elevation of 526 meters above sea level having hot climatic condition. Gambella town is located 768 kilometers away from Addis Ababa, the capital city of Ethiopia in the southwest direction. The town harbors different ethnic groups. The majority of ethnic groups residing in the town are Nuire, Agnuhak, and Mejenger. However, there are also other ethnic groups including settlers from other highlands of the country. According to population projection for 2014, based on the 2007 Census report Gambella town has a total population of 51,696, of whom 18,232 were women [24]. The town had a total of 10,152 households with an average of 3.8 persons to a household.

2.1.1. Study Design. A community based cross-sectional study was utilized to address the magnitude of undernutrition and its contextual determinants among pregnant mothers.

2.1.2. Population. A sample of pregnant women who resided in Gambella town for at least six months was included in the study. Pregnant women who refuse to participate and are severely ill were excluded from the study.

2.1.3. Sampling. Sample size was calculated using single population proportion formula by considering proportion of pregnant women undernourished as $50 \%$ since there was no prior study in lowlands of Ethiopia, 5\% margin of error, and 95\% confidence level. In addition, correction formula was used due to small number of pregnant women $(N=1,452)$ in the town during the study period. Finally, by addition of $10 \%$ nonresponse rate, the expected sample size was 338 pregnant women.

A survey was done to identify pregnant women in Gambella town prior to the actual study. Every women of reproductive age group in all residential households was asked for self-report of current pregnancy status. Women who were pregnant as per their oral report were further asked to show proof of pregnancy, ANC card from health facilities. These women, who reported pregnancy but had no evidence from health facility, were further tested for pregnancy using urine test (HCT test) in the field. Finally, a total of 1,452 pregnant women were found in the town during the study period. Samples of 338 pregnant women were selected randomly using computer after entering the total pregnant women in to SPSS software using unique numbers.

2.1.4. Data Collection Procedure and Measurement. Variables included and measured in this study were sociodemographic variables which comprise age, marital status, educational status, husband's educational status, occupation, husband's occupation, and family size; socioeconomic variables which comprise household income and household food insecurity; sociocultural variables which include early marriage, history of teenage pregnancy, living in polygamy, and intrahousehold 
food distribution; individual and behavioral variables like knowledge about nutrition, health service contact, dietary practice, birth interval, number of children born to the women, and latrine possession.

Data on sociodemographic, socioeconomic, sociocultural, household food insecurity, and individual and behavioral factors was collected by face-to-face interview using pretested questionnaires adapted from related literatures and translated to Amharic language. Household food insecurity was assessed using Household Food Insecurity Access Scale (HFIAS) measurement consisting of nine items [9]. Each of the questions under HFIAS was asked with a recall period of four weeks (30 days) prior to the data collection period. The respondent was first asked an occurrence question, that is, whether the condition in the question happened at all in the past four weeks (yes or no). If the respondent answers "yes" to an occurrence question, a frequency-of-occurrence question was asked to determine whether the condition happened rarely (once or twice), sometimes (three to ten times), or often (more than ten times) in the past four weeks. A $24 \mathrm{hr}$ dietary recall method was used to collect data on dietary intake.

Local languages speaking and fluent in Amharic diploma nurses were assigned as data collectors and verbally administered questionnaire to respondents. After conducting face-toface interview, mid upper arm circumference of the respondents was measured on the left hand at the mid point between the tips of the shoulder and elbow to the nearest $0.1 \mathrm{~cm}$ by using nonstretchable mid upper arm circumference (MUAC) tape. MUAC was used to assess nutritional status of pregnant women [25]. Five trained diploma nurses were data collectors and two B.S. public health officers were assigned as supervisors. Data collectors and supervisors were given two-day training focusing on participant selection procedure, MUAC measurement, ethical procedure, and objective of the study. The responsibilities of data collectors were measuring the mid upper arm circumference of the respondent and filling the questionnaires. The supervisor provides all items necessary for data collection on each data collection day, checking filled questionnaire for completeness and consistency and solving problems during data collection. Before conducting the main study, pretesting was done on 17 pregnant women residing in Abobo town of Gambella region. Finally, data collection tool was refined based on the findings from the pretesting. Every day, all collected data was reviewed and checked for completeness and consistency by the supervisors.

2.2. Data Processing and Analysis. Data were checked and edited for completeness and consistency and partially coded manually. Data were entered into EpiData version 3.1 and exported to SPSS version 16 for statistical analysis. Descriptive statistics were computed to explore frequency distribution, central tendency, variability (dispersion), and distribution of outcome and explanatory variables. Bivariable logistic regression was done to identify candidate variables ( $p$ value $=$ 0.2 ) for multivariable logistic regression analysis. To identify the independent predictors of undernutrition, multivariable logistic regression model was fitted using backward stepwise method. Interaction between different variables was checked using Breslow-Day test of homogeneity of strata specific odds ratios. Multicollinearity between different predictor variables was also checked using variance inflation factor (VIF). In multivariable logistic regression, adjusted odds ratio with its 95\% confidence interval was computed for variables maintained in the final model and statistical significance was declared by the confidence interval.

Individual dietary diversity score (IDDS) was calculated by summing a total of 14 food groups [(1) cereals; (2) vitamin A rich vegetables and tubers; (3) white roots and tubers; (4) dark green leafy vegetables; (5) other vegetables; (6) vitamin A rich fruits; (7) other fruits; (8) organ meat; (9) flesh meat; (10) eggs; (11) fish; (12) legumes, nuts, and seeds; (13) milk and milk products; and (14) oils and fats] consumed over reference period ( 24 hours before the data collection). For example, if one pregnant woman eats from each food group, her DDS will be 14 [26]. MUAC less than $21 \mathrm{~cm}$ in pregnant women was considered as undernutrition. Household food security is defined as a household which experiences none of the food insecurity (access) conditions or just experiences worry, but rarely, otherwise, food insecurity [26]. Dietary diversity score below six is said to be low dietary diversity score otherwise better.

2.2.1. Ethical Consideration. Ethical clearance letter was obtained from Institutional Review Board (IRB) of Jimma University. Permission letter to conduct the research was obtained from Gambella Regional Health Bureau. Prior to data collection, the participants were informed about the purpose of the study, their right to refuse participation and discontinue the interview or measurement, and their full right to say "no" (opt out), and it was clearly stated that their decision of "no" will not affect any of their right to health provisions intended for pregnant women. The interviewers discussed the issue of confidentiality and obtained verbal consent before the actual interviews were launched. For this purpose, a one page consent form was attached as cover page to each questionnaire. In addition, any identification information including the name of the participants was not written in the questionnaire. Undernourished pregnant women were linked to local nutritional programs in the area.

\section{Results}

3.1. Sociodemographic Characteristics. From the total 338 recruited pregnant women, twelve of them were refused to participate in the study, making the response rate $96.5 \%$, and four were with incomplete data. Complete data were collected on 322 pregnant women.

Mean age of the participants was 26.7 with standard deviation of $(S D \pm 5.2)$ years. Majority $(83.6 \%)$ of the participants were in the age range of 20 to 34 years. A tenth (10.2\%), fifth $(20.4 \%)$, and near to two-thirds $(64.9 \%)$ of pregnant women were unmarried, illiterate, and housewives, respectively. The mean family size was 5.5 with the standard deviation of \pm 2.7 ranging from 2 to 15 . One hundred thirtyseven $(42.5 \%)$ were living in a family which had more than five members (Table 1). 


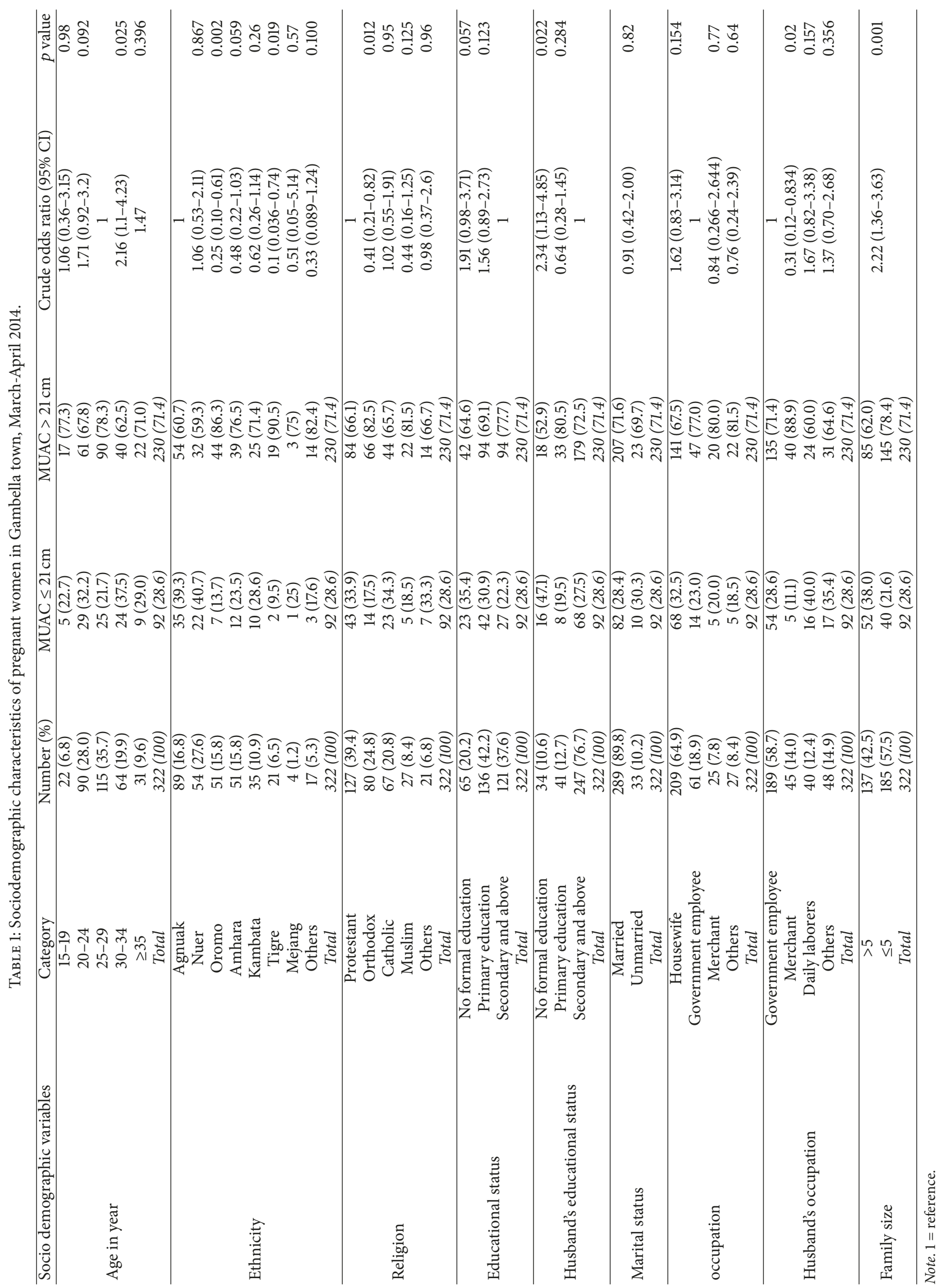


3.2. Prevalence of Undernutrition. The overall prevalence of undernutrition in lowland among pregnant women was $28.6 \%$. Pregnant women who were in the age group of $30-34$ years had higher prevalence $(37.5 \%)$ of undernutrition compared to the other age groups. Pregnant women and their husbands who are illiterate had higher prevalence of undernutrition (35.4\% and $47.1 \%$ ) compared to their counterparts, who completed secondary education and above. Pregnant women who were married before the age of eighteen and conceived before the age of twenty had higher undernutrition prevalence ( $46.8 \%$ and $43.4 \%$, resp.). Pregnant women who had meal frequency less than three and dietary diversity score (DDS) less than six had higher prevalence of undernutrition ( $45.8 \%$ and $41.5 \%$, resp.) compared to pregnant women who had meal frequency greater than or equal to three and DDS greater than or equal to six $(27.2 \%$ and $19.8 \%$, resp.). Near to half $(44.5 \%)$ of pregnant women living in food insecure households were undernourished whereas almost a fifth (16.8\%) of pregnant women living in food secure households were undernourished (Tables 2 and 4).

3.3. Individual, Household, and Sociocultural Characteristics. The median age at first marriage was 18 ranging from 14 to 31 years. One hundred forty-one (43.8\%) women were married before the age of eighteen. The mean age at first conception was 19.9 with the standard deviation of $(S D \pm 3.04)$ years ranging from 15 to 33 years of age. In two hundred forty-seven (76.7\%) households, diets were shared equally even though the foods to be eaten were small during meal. In fifty-four $(16.8 \%)$ households, foods were first given to husband and then shared among other family members. About one-third (33.2\%) pregnant women said that they eat their diet after serving their husband and children (Table 2).

According to report from pregnant women, 41 to $44 \%$ of the households either are worried about not having enough food, are unable to eat preferred food, or ate few food types a month before commencement of data collection. One hundred fourteen (35.4\%) households ate the foods they really do not want to eat while $28 \%$ of households ate a fewer meal a day during one month before data collection (Table 3 ).

From the total 322 pregnant women, $42.5 \%$ pregnant women were from food in secured households. Near to half $(46.9 \%)$ of pregnant women had no better nutritional knowledge. The mean meal frequency per day was 3.43 meals with a minimum of two and maximum of six meals per day. Twenty-four (7.5\%) pregnant women had eaten less than three meals a day. The mean dietary diversity score was 6 food groups out of 14 food groups with the standard deviation (SD) of \pm 1.58 ranging from 2 to 13 food groups (Table 4). From the fourteen food groups, cereal food group was eaten by $100 \%$ of the pregnant women. From the cereal food group "teff" (58.4\%) was the most consumed food followed by corn (54.7\%), wheat (43.5\%), and millet (36\%). "Injera" (62.1\%) and porridge (46\%) were the most processed food eaten from cereal group (Supplementary Material (available here)).

3.4. Predictors for Undernutrition among Pregnant Women. The following candidate variables from bivariable logistic regression were considered to multivariable logistic regression analysis: age, pregnant women and their husband's educational status, husband's occupation, family size, household's monthly income, household food insecurity, and dietary diversity. Similarly, nutritional knowledge, meal frequency, ANC visit, children size, latrine possession, and all sociocultural characterize of pregnant women were candidate variables to multivariable logistic regression analysis.

Multivariable logistic regression was fitted in order to identify independent predictors of undernutrition. Accordingly, early marriage, household food insecurity, and low dietary diversity score were independent predictors of undernutrition during pregnancy. Pregnant women who were married before the age of eighteen were nearly fourfold more likely to be undernourished compared to pregnant women who were married after the age of eighteen $(\mathrm{AOR}=3.9$, 95\% CI: 2.2-6.9). Pregnant women who were from food insecure households were nearly two times more likely to be undernourished compared to pregnant women who were from food secure households (AOR $=2.3,95 \%$ CI: 1.2-3.6). Pregnant women who had low dietary diversity score were two times more likely to be undernourished as compared to pregnant women who had better dietary diversity score (AOR $=2.1,95 \%$ CI: $1.3-4.1)$ (Table 5).

\section{Discussion}

The current study tried to reveal the magnitude of undernutrition and its associated factors among pregnant women in Gambella, lowland of Ethiopia. Accordingly the project highlighted that near thirty percent of pregnant women in lowlands were undernourished and mainly influenced by household food insecurity, eating low dietary diversity and early marriage.

The magnitude of undernutrition among pregnant women in Gambella town was $28.6 \%$. The result was almost similar tothe result reported from Kenya which was 31.7\% [27]. But magnitude of undernutrition reported in this study was far below the magnitude reported from Kersa Demographic Surveillance and Health Research Center (KDS-HRC) field site, Ethiopia, which was 47.3\% [28], $71.1 \%$ in Southern Nations, Nationalities and peoples region (SNNPR) [29], and 34\% in West Arsi Zone [22]. The big discrepancy observed may be due to different MUAC cut-off points used to determine undernutrition. However, the finding from this study was higher than other findings from highlands of Ethiopia 19.06\% from eastern Ethiopia [21].

Early marriage was one of the sociocultural factors which independently associated with undernutrition during pregnancy. The median age at first marriage was 18 years. This is almost consistent with the EDHS 2011 report in which the median age at first marriage in Gambella region was 17.4 years. But, it was above the national median age at first marriage which was 16.5 years [30]. The difference may be due to disparity of age at first marriage among urban and rural women. From pregnant women who were married before the age of eighteen, $66(46.8 \%)$ were undernourished whereas from those who married at their eighteen or more age, only $26(14.4 \%)$ were undernourished. Pregnant women who were married before the age of eighteen were nearly fourfold more 


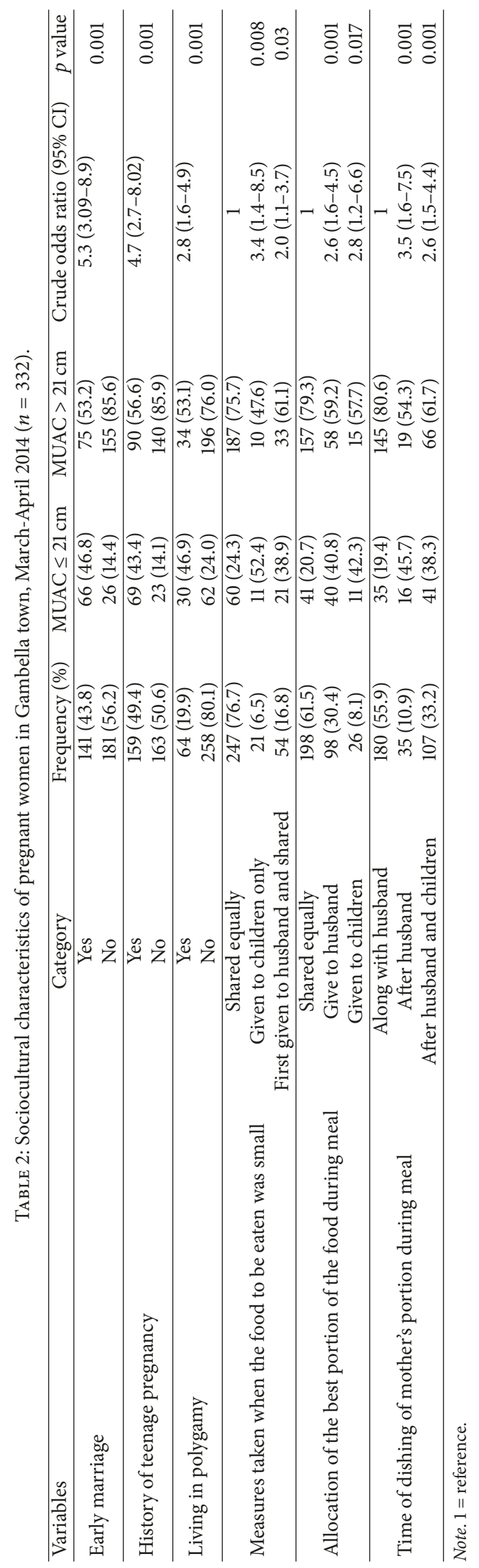


TABLE 3: Household food insecurity access scale (HFIAS) of pregnant women in Gambella town, $2014(n=332)$.

\begin{tabular}{lll}
\hline $\begin{array}{l}\text { Household food insecurity } \\
\text { access scale (HFIAS) }\end{array}$ & Frequency & Percentage \\
\hline
\end{tabular}

\begin{tabular}{lcc}
\hline Worry about food & & \\
Rarely & 37 & 11.5 \\
Sometimes & 78 & 24.2 \\
Often & 25 & 7.8 \\
No & 182 & 56.5
\end{tabular}

Unable to eat preferred

food

Rarely

Sometimes

69

Often

No

Eat just a few kind of food

Rarely

Sometimes

Often

70

No

Eat foods they really do not want to eat

\section{Rarely \\ Sometimes}

Often

No

Eat a smaller meal

Rarely

Sometimes

Often

Eat fewer meal in a day

$$
\text { Rarely }
$$

Often

$$
\text { No }
$$

No food of any kind in household

$$
\text { Rarely }
$$

Sometimes

No

Go to sleep hungry

$$
\text { Rarely }
$$

Sometimes

$$
\text { No }
$$

Go a whole day and night without eating

$$
\text { Rarely }
$$

likely to be undernourished compared to pregnant women who were married at or after the age of eighteen. This result is consistent with the study done in West Arsi, Ethiopia, in which pregnant women who married before the age of fifteen were sixteen times more likely undernourished compared to pregnant women who married between the ages of eighteen and nineteen years [22]. The 2012 USAID report on delaying age at marriage and reducing malnutrition of adolescent girls in India showed that early marriage was associated with early pregnancy and high fertility; close spacing of births, unwanted pregnancies, and pregnancy termination which cumulatively deteriorates nutritional status of adolescent girls [31].

Household food insecurity was also one of the socioeconomic factors which independently associated with undernutrition during pregnancy. Pregnant women who were from food insecure households were nearly two times more likely to be undernourished compared to pregnant women who were from food secured households. The result could be due to the fact that, in food insecure households, women pay a sacrificial role and are more vulnerable to be undernourished than other family members [7]. Pregnant women are particularly vulnerable to food insecurity and associated nutrient inadequacies for two major reasons. First, physiological vulnerability comes with childbearing. Maternal nutrient needs increase during pregnancy and breastfeeding, and when these needs are not met, mothers may experience wasting and fatigue. Second, women have a sociological vulnerability. Food security research indicates that, during periods of reduced food supply, women experience reduced intakes relative to men. Furthermore, mothers are likely to reduce their own intakes to secure those of infants and small children [32]. The Ethiopian national nutrition strategy also underpins that in food insecure households women and children are the most vulnerable groups and should be given special attention [7].

Low dietary diversity score was also independently associated with undernutrition. Pregnant women who had low DDS were two times more likely to be undernourished when they were compared with pregnant women who had better DDS. This is consistent with the result of survey done in Iran in which participants with scores $\geq$ six had greater body mass index, waist circumference, and waist-to hip ratio than in individuals with scores less than six [33]. The study is also similar to the community based study done in eastern Ethiopia in which pregnant women who improved their eating habits had a $53 \%$ lower risk of undernutrition than who did not [21]. The study done in Kenya also showed that pregnant women with better DDS had greater macro- and micronutrient intake when compared to pregnant women with low DDS [27].

This study had its own limitation; in that use of $24 \mathrm{hr}$ dietary recall questionnaire may lend itself to over or underestimation of dietary intake as it is dependent on the respondents' ability to recall their dietary intake and persistence of the interviewer. The single $24 \mathrm{hr}$ dietary recall method used in this study does not reflect seasonal variation of dietary intake. Similarly, household food insecurity and nutritional status during pregnancy may vary across seasons. 


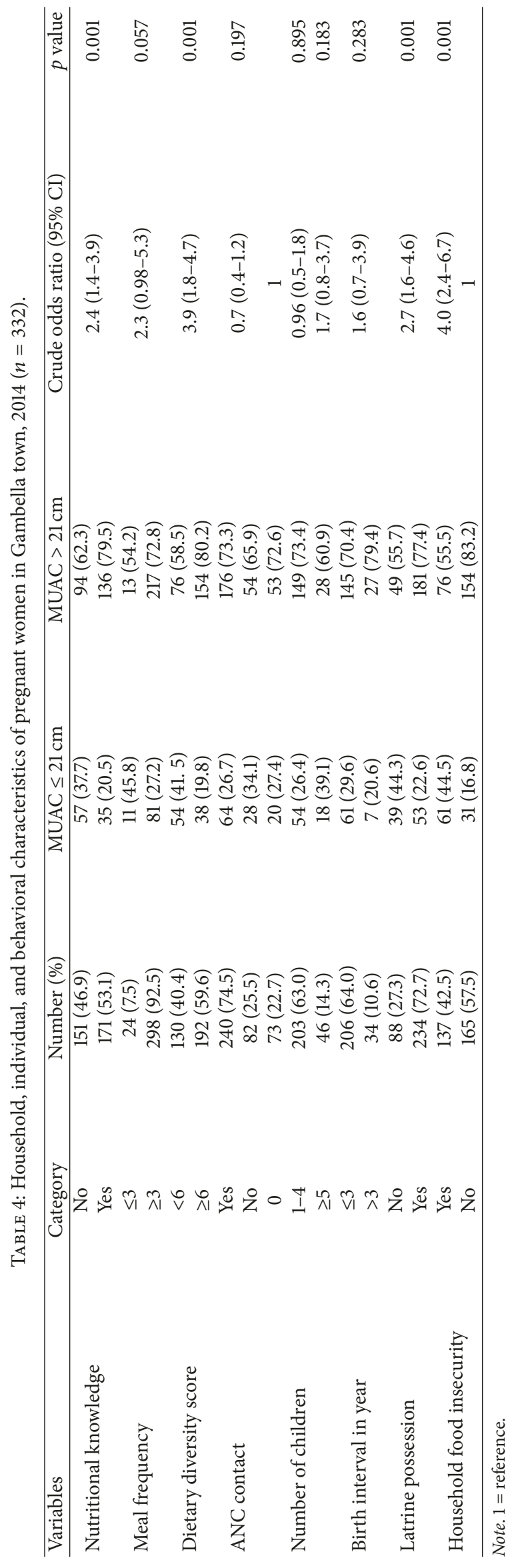


TABLE 5: Independent predictors of undernutrition among pregnant women in Gambella town, $2014(n=332)$.

\begin{tabular}{|c|c|c|c|c|c|c|}
\hline Variables & Category & Number (\%) & MUAC $\leq 21 \mathrm{~cm}$ & MUAC $>21 \mathrm{~cm}$ & Crude odds ratio $(95 \% \mathrm{CI})$ & Adjusted odds ratio $(95 \% \mathrm{CI})$ \\
\hline \multirow{2}{*}{ Early marriage } & Yes & $141(43.8)$ & $66(46.8)$ & $75(53.2)$ & \multirow{2}{*}{$5.3(3.1-8.9)^{*}$} & \multirow{2}{*}{$3.9(2.2-6.9)^{*}$} \\
\hline & No & $181(56.2)$ & $26(14.4)$ & $155(85.6)$ & & \\
\hline \multirow{2}{*}{$\begin{array}{l}\text { Dietary diversity } \\
\text { score }\end{array}$} & $<6$ & $130(40.4)$ & $54(41.5)$ & $76(58.5)$ & \multirow{2}{*}{$3.9(1.8-4.7)^{*}$} & \multirow{2}{*}{$2.1(1.2-3.6)^{*}$} \\
\hline & $\geq 6$ & $192(59.6)$ & $38(19.8)$ & $154(80.2)$ & & \\
\hline \multirow{2}{*}{$\begin{array}{l}\text { Household food } \\
\text { insecurity }\end{array}$} & Yes & $137(42.5)$ & $61(44.5)$ & $76(55.5)$ & \multirow{2}{*}{$4.0(2.4-6.7)^{*}$} & \multirow{2}{*}{$2.3(1.3-4.1)^{*}$} \\
\hline & No & $165(57.5)$ & $31(16.8)$ & $154(83.2)$ & & \\
\hline
\end{tabular}

${ }^{*} p$ value $<0.01$

\section{Conclusions}

This study found that the prevalence of undernutrition among pregnant women in Gambella town, lowland of Ethiopia, was within the range for highland area of Ethiopia, yet it is still unacceptably high. Household food insecurity, low dietary diversity score, and early marriage were independent predictors of undernutrition. Gambella region agricultural and rural development bureau should work in collaboration with other stakeholders to develop locally available crops to strengthen household food security and improve dietary diversity and quality. Responsible stake holders in the region should give due consideration to health education to delay age at first marriage. Further longitudinal study may be needed to fully understand household food insecurity and its relation to undernutrition across different seasons.

\section{Acronyms}

AOR: Adjusted odds ratio

cOR: Crude odds ratio

CSA: Central Statistical Agency

DDS: Dietary diversity score

EDHS: Ethiopian demographic and health survey

FAO: $\quad$ Food and Agriculture Organization

HCG: Human Chorionic Gonadotrophin

HFIAS: Household Food Insecurity Access Scale

IDDS: Individual diet diversity score

IUGR: Intrauterine Growth Restriction

JU: Jimma University

MDDS: Mean dietary diversity score

MOH: Ministry of Health

MUAC: Midupper arm circumference

OR: $\quad$ Odds ratio

PW: Pregnant woman

RDA: Recommended Daily Allowance

RDI: $\quad$ Reference Dietary Intake

SGA: $\quad$ Small for Gestational Age

SPSS: $\quad$ Statistical Package for Social Science

UNICEF: United Nation Children's Fund

USAID: United State Agency for International Development

WHO: World Health Organization.

\section{Disclosure}

Mamo Nigatu is a principal investigator.

\section{Conflicts of Interest}

The authors declare that there are no conflicts of interest.

\section{Authors' Contributions}

Mamo Nigatu, Tsegaye Tewolde, and Desta Hiko Gemeda made substantial contribution in conception, designing, data acquisition, statistical analysis, interpretation of the results, and drafting of the manuscript.

\section{Acknowledgments}

The authors are very grateful to Jimma University for financial support. They are also grateful to Gambella Regional Health Bureau for material support. Lastly, they would like to extend their thanks to research participants, data collectors, supervisors, and all friends who directly and indirectly supported them in preparing this scientific paper.

\section{Supplementary Materials}

Table 1: food groups consumed by pregnant women in Gambella town, $2014(n=332)$. (Supplementary Materials)

\section{References}

[1] WHO, Nutrition for Health and Development, Geneva, Switzerland, 2000, http://whqlibdoc.who.int/hq/.../WHO_NHD_00 .6.p.

[2] T. Benson, An assessment of the causes of malnutrition in Ethiopia A contribution to the formulation of a National Nutrition Strategy for Ethiopia, Addis Abeba, Ethiopia, 2005.

[3] L. S. Brown, "Nutrition requirements during pregnancy," in Nutrition Requirements During Pregnancy, pp. 1-24, Jones and Bartlett Publishers, 1st edition, 2009.

[4] M. Melkie Edris, H. Tekle, Y. Fitaw, B. Gelaw, and Dagnew Engedaw. T. A., Maternal Nutrition:For the Ethiopian Health Center Team, Addis Abeba, Ethiopia, 2005.

[5] A. Bendich, Nutrition and Health, C. J. Lammi-Keefe, S. C. Couch, and EHP, Eds., Human Press, 2nd edition, 2008.

[6] Unicef, Improving Child Nutrition, New York, NY, USA, 2013, http://www.unicef.org/publications/index.htm.

[7] FMOH, National-Nutrition-Strategy.pdf., Addis Abeba, 2008.

[8] IYCN, Guidance for Formative Research on Maternal Nutrition, Washington, DC, USA, 2011.

[9] Worldbank, Repositioning Nutrition as Central to Development, Washington, DC, USA, 2006. 
[10] R. E. Black, C. G. Victora, S. P. Walker et al., "Maternal and child undernutrition and overweight in low-income and middleincome countries," The Lancet, vol. 382, no. 9890, pp. 427-451, 2013.

[11] K. Haileslassie, A. Mulugeta, and M. Girma, "Feeding practices, nutritional status and associated factors of lactating women in Samre Woreda, South Eastern Zone of Tigray, Ethiopia," Nutrition Journal, p. 28, 2013.

[12] J. A. Opara, H. E. Adebola, N. S. Oguzor, S. A. Abere, and P. Harcourt, "Malnutrition during pregnancy among child bearing mothers in mbaitolu of south-eastern nigeria federal college of education ( technical ), omoku-rivers state, nigeria faculty of agriculture, rivers state university of science and technology," Advances in Biological Research, vol. 5, no. 2, pp. 111-115, 2011.

[13] D. Assefa, E. Wassie, M. Getahun, M. Berhaneselassie, and A. Melaku, Harmful Traditional Practices, Addis Abeba, Ethiopia, 2005.

[14] K. Abu-Saad and D. Fraser, "Maternal nutrition and birth outcomes," Epidemiologic Reviews, vol. 32, no. 1, pp. 5-25, 2010.

[15] F. Khoushabi and G. Saraswathi, "Association between maternal nutrition status and birth weight of neonates in selected hospitals in Mysore city, India," Pakistan Journal of Nutrition, vol. 9, no. 12, pp. 1124-1130, 2010.

[16] Savethechildren, Surviving the First Day, STATE OF THE WORLD'S MOTHERS, London; 2013, http://www.savethechildren.net.

[17] S. Huffman, E. Zehner, P. Harvey et al., Essential Health Sector Actions to Improve Maternal Nutrition in Africa, Washington, DC, USA, 2001, http://www.linkagesproject.org.

[18] S. E. Lee, S. A. Talegawkar, M. Merialdi, and L. E. Caulfield, "Dietary intakes of women during pregnancy in low- and middle-income countries," Public Health Nutrition, vol. 16, no. 8, pp. 1340-1353, 2013.

[19] F. H. Bitew and D. S. Telake, "Undernutrition among Women in Ethiopia. Bitew, Fikrewold H. and Daniel S. Telake. 2010. Undernutrition among Women in Ethiopia: Rural-Urban Disparity. DHS Working Papers No. 77," Tech. Rep. Report No.: 77, ICF Macro, Calverton, Md, USA, 2010.

[20] G. Woldemariam and G. Timotiows, Determinants of the Nutritional Status of Mothers and Children in Ethiopia, Calverton, Maryland, USA, 2002.

[21] H. Kedir, Y. Berhane, and A. Worku, "Magnitude and determinants of malnutrition among pregnant women in eastern Ethiopia: Evidence from rural, community-based setting," Maternal \& Child Nutrition, vol. 12, no. 1, pp. 51-63, 2016.

[22] Y. Belete, B. Negga, and M. Firehiwot, "Under nutrition and associated factors among adolescent pregnant women in Shashemenne District, West Arsi Zone, Ethiopia: a community- based," Journal of Nutrition \& Food Sciences, vol. 6, no. 1, pp. 1-7, 2016.

[23] A. Sewonet, Breaking the Cycle of Conflict in Gambella Region, Addis Abeba, Ethiopia, 2003.

[24] C. Statistical, 2007 Population and Housing Census of Administrative, Addis Abeba, Ethiopia, 2012.

[25] FMOH, Nutritin Blended Learning Module for the Health Extension Programme, Health Education and Training in Africa, Addis Abeba, Ethiopia, 1st edition, 2004, Tom Heller and Lesley-Anne Long (Faculty of Health and Social Care at The Open University UK) http://www.moh.gov.et.

[26] FAO, Guidelines for Measuring Household and Individual Dietary Diversity, Rome, Italy, 2008.
[27] M. Lillian, Dietary Diversity and Nutritional Status of Pregnant Women Aged 15-49 YearS Attending Kapenguria District Hospital West Pokot County, Kenya, East Africa, 2013, https://www.lappublishing.com/.../dietary-diversity-and-nutritional-statu.

[28] N. Assefa, Y. Berhane, and A. Worku, "Wealth status, mid upper arm circumference (MUAC) and Ante Natal Care (ANC) are determinants for low birth weight in Kersa, Ethiopia," PLoS ONE, vol. 7, no. 6, Article ID e39957, 2012.

[29] A. Sonko, "Assessment of dietary practice and anthropometric status of pregnant women in Aleta Chuko Woreda Southern Nations, Nationalities and People's ${ }^{\mathrm{TM}}$ Region /SNNPR/, Ethiopia: descriptive crosssectional study," Journal of Epidemiology and Public Health Reviews, vol. 1, no. 1, pp. 1-8, 2016.

[30] EDHS, Ethiopia Demographic and Health Survey, Addis Abeba, Ethiopia, 2011.

[31] USAID, Delaying Age of Marriage and Reducing Anaemia Among Adolescent Girls in Jharkhand, Mumbai, India, 2012, http://www.intrahealth.org/vistaar.

[32] USAID, Maternal dietary diversity and the implications for children's diets in the context of food security, 2012, http://www.iycn .org.

[33] M. Vakili, P. Abedi, M. Sharifi, and M. Hosseini, "Dietary diversity and its related factors among adolescents: a survey in Ahvaz-Iran," Global Journal of Health Science, vol. 5, no. 2, pp. 181-186, 2013. 


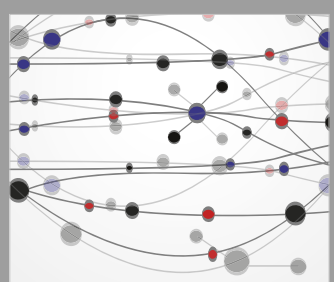

The Scientific World Journal
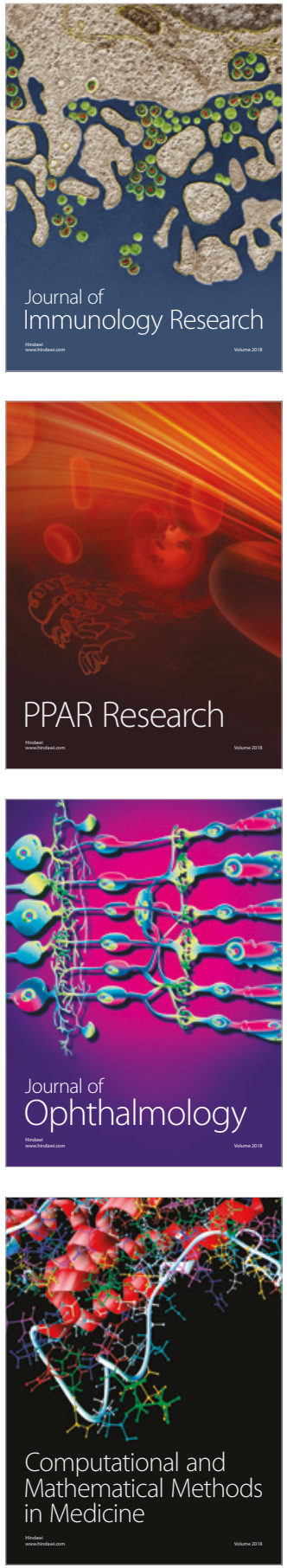

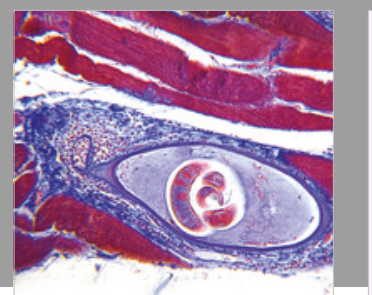

Gastroenterology Research and Practice

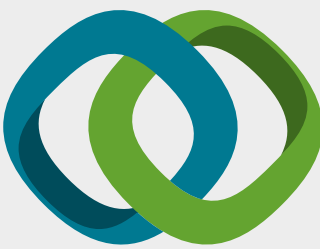

\section{Hindawi}

Submit your manuscripts at

www.hindawi.com
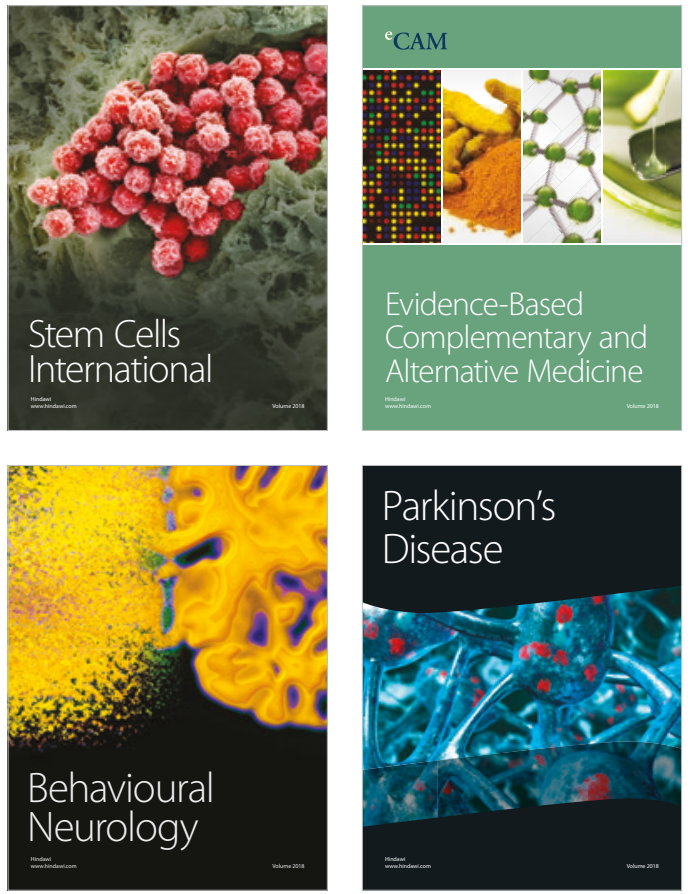

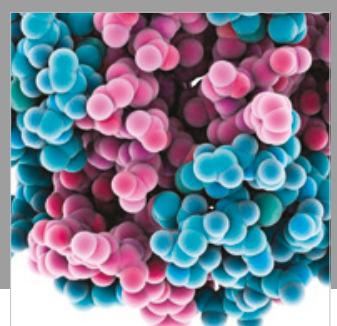

ournal of

Diabetes Research

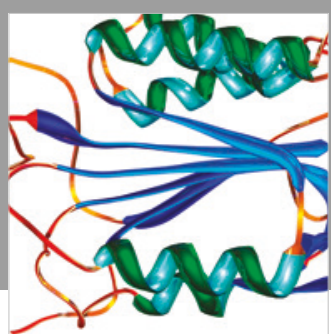

Disease Markers
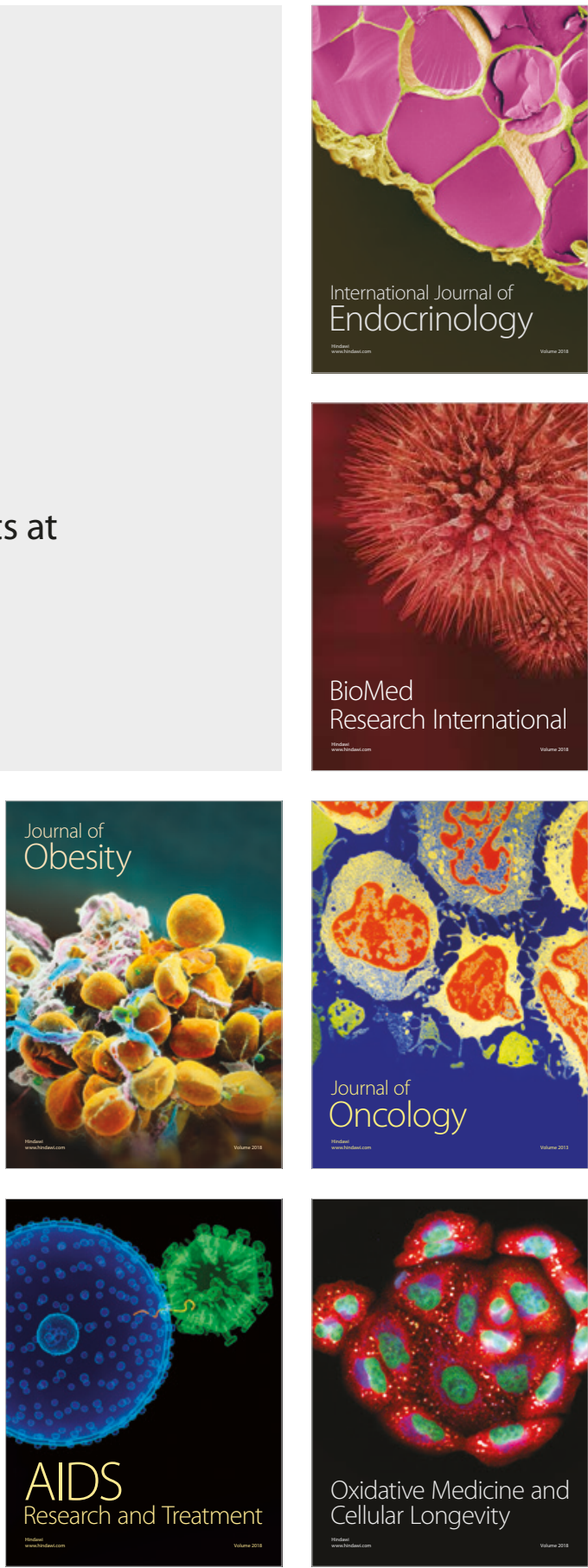